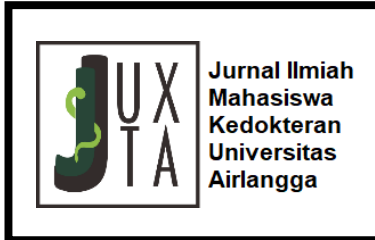

\title{
Profile of Acyanotic Congenital Heart Defect in Children at Dr. Soetomo General Hospital Surabaya Period of January - December 2016
}

\author{
Katherine Fedora ${ }^{1}$, I Ketut Alit Utamayasa ${ }^{2}$, Sri Purwaningsih ${ }^{3}$
}

\author{
${ }^{1}$ Faculty of Medicine, Universitas Airlangga - Dr. Soetomo General Hospital, Surabaya, Indonesia \\ 2 Department of Paediatrics, Faculty of Medicine, Universitas Airlangga - Dr. Soetomo General Hospital, Surabaya, Indonesia \\ 3 Department of Pharmacology, Faculty of Medicine, Universitas Airlangga - Dr. Soetomo General Hospital, Surabaya, \\ Indonesia
}

\section{A B S T R ACT}

Introduction: Acyanotic congenital heart defect is a congenital structural abnormality arising from incomplete formation of the heart or major blood vessels which generally do not interfere with the amount of oxygen or blood that reaches the body's tissues so that cyanosis are rarely found in these patients. This research aims to evaluate the profile of acyanotic congenital heart defect patients in Paediatric Cardiology Outpatient Clinic Dr. Soetomo General Hospital Surabaya period of January - December 2016 based on 4 variables; gender, age, nutritional status, type of congenital heart disease and symptoms. Until 2017, the profile of acyanotic congenital heart defect in children in Outpatient Unit of Paediatrics Department Dr. Soetomo General Hospital Surabaya has not been much researched, so this research is expected to be used as learning reference for practitioners and other readers, and also as a reference in developing management strategies for children with acyanotic congenital heart defect in the future.

Methods: This was a descriptive non-experimental study using cross-sectional design and was performed by evaluating medical record of acyanotic congenital heart defect patients in Department of Paediatrics Dr. Soetomo General Hospital Surabaya period of January - December 2016 and analysed using Microsoft Excel.

Results: The results of this study revealed that majority of acyanotic congenital heart defect patients were female (53.85\%) with age range between $0-<5$ years old. Atrial septal defect (ASD) was the most common type of acyanotic congenital heart defect $(49.8 \%)$, with sign and symptom that is commonly found in patients were failure to thrive $(61.94 \%)$. Majority of patients also suffered from growth disruption with most of patients aged $0-<5$ years old are severely underweight $(42.46 \%)$ and most of patients aged $5-18$ years old are having malnutrition (38.23\%).

\section{*Correspondence: alit_tusari@yahoo.com}

JUXTA: Jurnal IImiah Mahasiswa Kedokteran Universitas Airlangga

p-ISSN: 1907-3623; e-ISSN: 2684-9453

DOI: 10.20473/juxta.V10I22019.79-82

Open access under Creative Commons Attribution-ShareAlike 4.0 International License (CC-BY-SA)

\section{ARTICLE INFO}

Article history:

Received 05 August 2019

Received in revised form 16 August 2019

Accepted 20 August 2019

Keywords:

Acyanotic,

Congenital heart defect,

Children,

Paediatrics,

Growth. 


\section{Introduction}

Congenital heart defect is a structural disorder that arises from the formation of the heart or the main blood vessels present at birth. This disorder can involve the walls of the heart, heart valves, or arteries and veins near the heart. Disruption of the compartment can interfere with blood flow through the heart. Blood flow can be slowed down, flow to the wrong direction, or be completely blocked. ${ }^{1,2}$

Until now, the etiology of the cause of congenital heart defect is still unknown. However, there are several factors that are thought to increase the risk of developing congenital heart defect in children, such as heredity, genetic disorders, and smoking habits. Parents who have congenital heart abnormalities are more likely to have children with congenital heart defect. Children who have genetic disorders, such as Down syndrome, often have congenital heart defects. Smoking during pregnancy has also been linked to several congenital heart disorders, including cardiac septal defects. ${ }^{1,2}$

Congenital heart defect can be classified into cyanotic or acyanotic congenital heart defect. Cyanotic congenital heart defect is abnormalities that allow blood with low oxygen levels to be distributed to body tissues, this causes bluish color (cyanosis) on the skin, lips and nails. Meanwhile acyanotic congenital heart defect usually does not interfere with the amount of oxygen or blood that reaches the body's tissues, so cyanosis symptoms are rarely found in these patients. ${ }^{2}$

This study was intended to determine the profile of acyanotic congenital heart defect patients in Paediatric Cardiology Outpatient Clinic Dr. Soetomo General Hospital Surabaya period of January - December 2016.

\section{Methods}

This was a descriptive non-experimental study using cross-sectional design. The study was conducted at the Paediatric Cardiology Outpatient Clinic, Dr. Soetomo General Hospital Surabaya, from January to April 2018. The population studied were all patients with acyanotic congenital heart defect who were treated at Paediatric Cardiology Outpatient Clinic, Dr. Soetomo General Hospital Surabaya. This study obtained data from clinical history and medical records of patients with acyanotic congenital heart defect. Data were analysed with descriptive statistics and presented in frequency distribution tables.

\section{Results}

A total of 247 patients in outpatient unit of paediatric department was included in this study. There were $46.1 \%$ males and $53.8 \%$ were females, with a male to female ratio of $1: 1.2$. In this study, $72.5 \%$ were diagnosed by 5 years of age, $19 \%$ by $5-<11$ years, and $8.5 \%$ by $11-18$ years. Based on WHO growth standard for children aged below 5 years old, $42.5 \%$ were categorized as severely underweight, $20.1 \%$ as underweight, $36.3 \%$ as normal weight, and $1.1 \%$ above the normal range. For children aged 5-18 years old, nutritional status is categorized based on the classification by Indonesian Ministry of Health 1974 and reveals that $22.1 \%$ were categorized as malnutrition, $38.23 \%$ as undernutrition, $26.5 \%$ in the normal range, and $13.2 \%$ above the normal range. Atrial septal defect was the most frequent type, followed by ventricular septal defect, patent ductus arteriosus, pulmonary valve stenosis, aortic valve stenosis, and coarctation of aorta, with the number of $49.8 \%, 45.7 \%, 26.3 \%, 12.5 \%, 1.6 \%$, and $0.4 \%$ respectively. There was not any patient with atrioventricular septal defect found in this study. The most frequent sign and symptom that was found in this study is failure to thrive $(61.9 \%)$, heart murmurs $(55.1 \%)$, cough $(25.1 \%)$, shortness breath (17.4\%), and runny nose (16.2\%).

Table 1. General characteristic of the patients.

\begin{tabular}{lc}
\hline \multicolumn{1}{c}{ Characteristics } & $\begin{array}{c}\text { Number of } \\
\text { patients }\end{array}$ \\
\hline Gender & $133(53.85 \%)$ \\
Male & $114(46.15 \%)$ \\
Female & \\
Age & $179(72.47 \%)$ \\
$0-<5$ years old & $47(19.03 \%)$ \\
$5-<11$ years old & $21(8.50 \%)$ \\
$11-18$ years old & \\
Growth status & \\
Age $<5$ years old & $76(42.46 \%)$ \\
Severely underweight & $36(20.11 \%)$ \\
Underweight & $65(36.31 \%)$ \\
Normal & $2(1.12 \%)$ \\
Above the normal range & \\
Age 5 - 18 years old & $15(22.06 \%)$ \\
Malnutrition & $26(38.23 \%)$ \\
Undernutrition & $18(26.50 \%)$ \\
Normal & $9(13.23 \%)$ \\
Above the normal range &
\end{tabular}

Source: research data, processed

Table 2. Types of acyanotic congenital heart defect of the patients.

\begin{tabular}{lc}
\hline \multicolumn{1}{c}{ Types of defect } & $\begin{array}{c}\text { Number of } \\
\text { patients }\end{array}$ \\
\hline Atrial septal defect (ASD) & $123(49.80 \%)$ \\
Ventricular septal defect (VSD) & $113(45.75 \%)$ \\
Patent ductus arteriosus (PDA) & $65(26.31 \%)$ \\
Pulmonary valve stenosis & $31(12.55 \%)$ \\
Aortic valve stenosis & $4(1.62 \%)$ \\
Coarctation of aorta & $1(0.40 \%)$ \\
Atrioventricular septal defect & $0(0 \%)$ \\
\hline Source: research data, processed &
\end{tabular}


Table 3. Sign and symptoms of the patients.

\begin{tabular}{lc}
\hline \multicolumn{1}{c}{ Sign and symptoms } & Number of patients \\
\hline Failure to thrive & $153(61.94 \%)$ \\
Heart murmur & $136(55.06 \%)$ \\
Cough & $62(25.10 \%)$ \\
Dyspnea & $42(17.40 \%)$ \\
Runny nose & $40(16.19 \%)$ \\
Fever & $30(12.14 \%)$ \\
Cyanosis & $26(10.53 \%)$ \\
Edema & $25(10.12 \%)$ \\
Chest pain & $6(2.43 \%)$ \\
Vomit & $6(2.43 \%)$ \\
Clubbing finger & $5(2.02 \%)$ \\
Icterus & $5(2.02 \%)$ \\
Palpitation & $4(1.62 \%)$ \\
Sweating & $3(1.21 \%)$ \\
Seizure & $2(0.81 \%)$ \\
Regurgitation & $2(0.81 \%)$ \\
Lethargic & $2(0.81 \%)$ \\
Liquid stool & $2(0.81 \%)$ \\
Headache & $1(0.40 \%)$ \\
Retraction & $1(0.40 \%)$ \\
Syncope & $1(0.40 \%)$ \\
Hemoptoe & $1(0.40 \%)$ \\
Decreased appetite & $1(0.40 \%)$ \\
Nausea & $1(0.40 \%)$ \\
Sore throat & $1(0.40 \%)$ \\
Melena & $1(0.40 \%)$ \\
Restless & $1(0.40 \%)$ \\
\hline Source:research data, &
\end{tabular}

Source: research data, processed

\section{Discussion}

\section{Gender Difference in Acyanotic Congenital Heart Defect Patients}

Females are predicted to have higher number of incidents compared to males. This can be affected by the presence of biological differences in the structure of blood vessels, in which the diameter of arteries in female is smaller than male. ${ }^{3}$ This condition increases the risk of vascular endothelial dysfunction, thereby contributing to the occurrence of pulmonary hypertension. ${ }^{3}$ Spontaneous septal defect closure is more common in males than females. ${ }^{4}$ This supports the results of this study that shows $55.75 \%$ patients with ventricular septal defect were females and $44.25 \%$ were males, while $53.66 \%$ patients with atrial septal defect were females and $46.34 \%$ were males. Several studies are in accordance with the results of this study, which showed that female patients had a higher number rather than males. Previous study conducted by Didik Hariyanto (2012) in Padang showed that among patients with acyanotic congenital heart defect, $51 \%$ were females and $49 \%$ males. Other study by Ain et al. (2015) in Padang revealed that number of female patients were $61.8 \%$, while $38.2 \%$ other were males.

\section{Age Distribution in Acyanotic Congenital Heart Defect Patients}

The difference in the age of diagnosis in children with acyanotic congenital heart defect depends on the type and complexity of the defects. ${ }^{5}$ Some patients may show typical symptoms in early life, while others may only be showing minimal symptoms such as recurrent respiratory infections or difficulty in gaining weight, that makes it rarely detected until adulthood. ${ }^{5}$ The high number of patients under 5 year of age shows a very good referral system and early diagnosis. ${ }^{5}$ Several studies that have been done before, one of them by Ain et al. (2015), revealed that majority of patients with acyanotic congenital heart defect in RSUP M. Djamil Padang were under 1 year of age with the frequency of $56.4 \%$, while the remaining $43.6 \%$ were above 1 year old. The result is also in accordance with previous study by Didik Hariyanto (2012) in Padang, that $62.2 \%$ of patients with acyanotic congenital heart defect were under 1 year of age, while the remaining $37.8 \%$ were over 1 year old.

\section{Growth Status of Acyanotic Congenital Heart Defect Patients}

The presence of congenital defect in the heart structure increase the metabolic demand and total energy expenditure of the body, while reduced body mass presentation tends to increase the basal metabolic rate, which if not treated properly will worsen the child's health condition. ${ }^{6}$

Acyanotic congenital heart defect also tends to cause congestive heart failure, that leads to decrease in cardiac output and water and salt retention. ${ }^{7}$ Therefore, the tissue oxygen demand is not met optimally and causes the child growth to be hampered. ${ }^{7}$

Other than that, symptoms experienced by children with congestive heart failure such as dyspnea and tachypnea that appear during eating cause children to feel tired, loss of appetite, and lead to a decrease in the quantity of food consumed by children. ${ }^{8}$

Decrease of ghrelin in blood is also noted in acyanotic congenital heart defect patients. ${ }^{6}$ Ghrelin causes inhibition of leptin, so it can be concluded that if there is a decrease in ghrelin levels, it can be predicted there will be an increase in leptin levels in blood. ${ }^{6}$ Both of these peptides play a role in the development of anorexia-cachexia syndrome in children, metabolic conditions characterized by anorexia, negative energy balance, weight loss, and muscle atrophy. ${ }^{6}$ Increased levels of leptin in the blood also causes activation of the melanocortin system, which then increases the body's energy expenditure and decreases appetite. ${ }^{7}$

The presence of concomitant infections also plays an important role through release of proinflammatory cytokines such as TNF- $\alpha$ which induces cell apoptosis, tissue proteins breakdown, and increases leptin secretion into the blood. ${ }^{7}$ This mechanism causes the body's protein reserves to decrease, decreased appetite, and increased body's energy expenditure. $^{7}$

There was also an association between chronic hypoxemia and endocrine function in patients with 
congenital heart defect. ${ }^{8}$ Chronic hypoxemia can cause a decrease in IGF-1 levels in the blood, a peptide that plays in important role in growth, so that the growth of body tissue cannot be achieved optimally. ${ }^{8}$ Although chronic hypoxemia is more common in cyanotic congenital heart defect compared to acyanotic, this mechanism still can be one of the causes of failure to thrive in children with acyanotic congenital heart defect. ${ }^{8}$

Growth pattern in acyanotic congenital heart defect patients influenced by several factors such as type of congenital heart defect, presence of gastrointestinal disorder, and presence of chromosomal abnormalities. ${ }^{6}$ The degree of failure to thrive in children is directly proportional to the size of the shunt, therefore children with congenital heart defect without a shunt may show normal pattern of growth. ${ }^{6}$

\section{Types of Acyanotic Congenital Heart Defect}

Congenital heart defect is strongly influenced by genetic factors, although it is also influenced by environmental factors. According to research conducted by Fahed et al. in 2002, there were 25 genes that affect the formation of congenital heart defects, especially related to acyanotic congenital heart defect. Out of the 25 genes, 13 of them induced the formation of atrial septal defects (ASD), namely mutations from the genes CITED2, GATA4, GATA6, NKX2.5, TBX5, TBX20, ZIC3, CFC1, CRELD1, GJA1, ACTC, MYH6, and MYH7. Meanwhile 10 of the 25 genes induced the formation of ventricular septal defects (VSD), namely mutations from the genes CITED2, GATA4, GATA6, IRX4, NKX2.5, TBX5, TBX20, ZIC3, CFC1, and TOGF1. Therefore, based on the theory, the chance of $A S D$ formation is higher than VSD. ${ }^{9}$

However, ASD is usually presented asymptomatic or with very smooth murmur, this defect often does not lead to early diagnosis. ${ }^{10}$ The high number of patients with ASD shows a very good early diagnosis system. ${ }^{10}$

Table 4. Comparative study of lesions with other studies.

\begin{tabular}{lccccc}
\hline \multicolumn{1}{c}{$\begin{array}{c}\text { Types of acyanotic } \\
\text { congenital heart defect }\end{array}$} & $\begin{array}{c}\text { Gupta et al., } \\
\mathbf{2 0 1 6} \text { (India) }\end{array}$ & $\begin{array}{c}\text { Ain et al., } \\
\mathbf{2 0 1 5} \\
\text { (Indonesia) }\end{array}$ & $\begin{array}{c}\text { Bhardwaj et } \\
\text { al., 2015 } \\
\text { (India) }\end{array}$ & $\begin{array}{c}\text { Didik H., } \\
\mathbf{2 0 1 2} \\
\text { (Indonesia) }\end{array}$ & $\begin{array}{c}\text { American } \\
\text { Heart } \\
\text { Association }\end{array}$ \\
\hline Atrial septal defect & $20.34 \%$ & $22.73 \%$ & $29.10 \%$ & $30.97 \%$ & $28.16 \%$ \\
Ventricular septal defect & $52.41 \%$ & $50 \%$ & $50.81 \%$ & $30.97 \%$ & $30.06 \%$ \\
Patent ductus arteriosus & $13.10 \%$ & $18.18 \%$ & $6.23 \%$ & $29.20 \%$ & $21.69 \%$ \\
Pulmonary valve stenosis & $6.00 \%$ & $4.54 \%$ & $2.31 \%$ & $8.85 \%$ & $20.18 \%$ \\
Aortic valve stenosis & $0.33 \%$ & - & $0.92 \%$ & - & - \\
Coarctation of aorta & $0.33 \%$ & - & $0.92 \%$ & - & - \\
Atrioventricular septal defect & $1 \%$ & $4.54 \%$ & $9.70 \%$ & - & - \\
\hline
\end{tabular}

Sign and Symptoms Distribution in Acyanotic Congenital Heart Defect Patients

The most common symptom found in acyanotic congenital heart defect patients is failure to thrive that is already described above. Heart murmurs also found in majority of the patients because the presence of heart valve structure abnormalities or shunt in heart septum makes the blood flow becomes abnormal and causes turbulence that is heard as heart murmurs. ${ }^{11}$ This abnormal blood flow allows blood from the left side of the heart to flow to the right side of the heart due to the pressure difference between the two parts of the heart. ${ }^{11}$ Therefore, right ventricular blood volume increases, and the flow of blood to the lungs through pulmonary artery also increases. ${ }^{12}$ An increase in blood volume increases pulmonary artery pressure in which develops further into pulmonary hypertension. ${ }^{12}$ If the volume exceeds its maximum capacity then fluid enter the interstitial space and accumulate in the alveoli, it can cause symptoms of breathing difficulties in patient due to thickening of the barrier for oxygen exchange. ${ }^{12}$ Besides, the accumulated fluid in the lungs tries to be excreted by the patient by coughing. ${ }^{13}$

Abnormal blood flow also causes a decrease in cardiac output and develop congestive heart failure which is often characterized by edema. ${ }^{14}$ Decreased cardiac output causes the volume of blood distributed throughout the body decrease, so that the blood pressure decreases and induces the activation of baroreceptor reflexes which aim to increase blood vessel pressure to return to normal. The presence of baroreceptor stimulation activates the sympathetic nervous system which then causes an increase in heart rate that is experienced by patients as palpitation. ${ }^{15,16}$ Not only affects the heart, the sympathetic nervous system also activates the skin effectors including sweat glands that has the effect of increasing sweat secretion. ${ }^{17,18}$

The risk of respiratory infection is increased in patients with acyanotic congenital heart defects, this may contribute to the onset of runny nose as a sign of upper respiratory tract infections and coughing as a sign of lower respiratory tract infections. ${ }^{19}$ Malnutrition also affects the immune system, therefore increasing the risk of infection and slowing down the healing process. ${ }^{20}$ 


\section{Conclusion}

Distribution of acyanotic congenital heart defect patients in this study were dominated by female $(53.85 \%)$ between $0-<5$ years old $(48.58 \%)$. Majority of patients under 5 years old were having malnutrition (42.46\%), while patients above 5 years old were mostly underweight (38.23\%). Type of acyanotic congenital heart defect most commonly found in RSUD Dr. Soetomo General Hospital Surabaya was atrial septal defect $(49.8 \%)$, with symptoms that are often complained by patients were failure to thrive (61.94\%). This research is expected to be used as learning reference for practitioners and other readers, and also as a reference in developing management strategies for children with acyanotic congenital heart defect in Outpatient Unit of Paediatrics Department Dr. Soetomo General Hospital Surabaya in the future. If the same research is carried out in the next period, researchers are expected to be able to compare with the data of this study so that the results will be more comprehensive.

\section{CONFLICT OF INTEREST}

The author stated there is no conflict of interest in this study.

\section{REFERENCES}

1.Health Nlo. Congenital Heart Defects. Maryland: National Heart, Lung, and Blood Institutes, 2015.

2.Lurcook K and Stepney G. Congenital Heart Disease. Oxford University Hospitals. 2016: 2-3.

3.Verheugt CL, Uiterwaal CS, van der Velde ET, et al. Gender and outcome in adult congenital heart disease. Circulation. 2008; 118: 26-32.

4.Warnes CA. Sex Differences in Congenital Heart Disease. Circulation. 2008; 118: 3-5.

5.Abah R, Ochoga M, Audu O, Idoko A, Eseigbe E and JO D. Pattern of Cardiac Disease among Children in a Tertiary Hospital in North Central, Nigeria: A Three and Half Years Retrospective Cohort Echocardiographic Study. African Journals Online. 2018; 45: 6-9.

6.Argent AC, Balachandran R, Vaidyanathan B, Khan A and Kumar RK. Management of undernutrition and failure to thrive in children with congenital heart disease in low- and middle-income countries. Cardiology in the young. 2017; 27: S22-s30.

7.Mangili G, Garzoli E and Sadou Y. Feeding dysfunctions and failure to thrive in neonates with congenital heart diseases. La Pediatria medica e chirurgica : Medical and surgical pediatrics. 2018; 40.

8.Togănel R. Nutritional Approach of Pediatric Patients Diagnosed with Congenital Heart Disease. 2013; 59: 121.

9.Fahed AC, Gelb BD, Seidman JG and Seidman CE. Genetics of Congenital Heart Disease. Circulation Research. 2013; 112: 707-20.

10.Hoffman $\mathrm{JI}$ and Kaplan S. The incidence of congenital heart disease. Journal of the American College of Cardiology. 2002; 39: 1890-900.

11.Aly $\mathrm{A}$ and Dasgupta S. Heart Murmurs. Cardiology: $A$ Chapter in Core Concepts of Pediatrics. 2nd ed. Texas: Department of Pediatrics, University of Texas Medical Branch, 2017.

12.Scotland CHaS. Congenital Heart Disease: (2017).
13.Fogoros RN. Coughing and Heart Failure: Cardiac Cough Explained. 2018.

14.Sharma M, Nair M, Jatana SK and Shahi BN. Congestive Heart Failure in Infants and Children. Med J Armed Forces India. 2003; 59: 228-33.

15.Malik A, Brito D and Chhabra L. Heart Failure, Congestive (CHF). Florida: StatPearls Publishing LLC, 2017.

16.Karemaker JM. An introduction into autonomic nervous function. Physiological measurement. 2017; 38: R89-r118.

17.Stewart J, Manmathan $G$ and Wilkinson P. Primary prevention of cardiovascular disease: A review of contemporary guidance and literature. JRSM cardiovascular disease. 2017; 6: 2048004016687211.

18.Sarkar M, Niranjan N and Banyal PK. Mechanisms of hypoxemia. Lung India. 2017; 34: 47-60.

19.Gabriela K, Kuswiyanto RB and Dwiyatnaningrum F. Clinical Characteristic and Outcome of Acute Lower Respiratory Tract Infection in Children with Congenital Heart Disease. Althea Medical Journal. 2015; 2: 403-8.

20. Morales R, Meija B, Olave A and Betancourt C. Nutrition and Infection. Encyclopedia of Food and Health. 2016. 